DSCC2017-5040

\title{
A FORCE SENSING INSTRUMENT ASSISTED SOFT TISSUE MOBILIZATION DEVICE
}

\author{
Ahmed M. Alotaibi \\ Department of Mechanical Engineering \\ Purdue University \\ West Lafayette, IN, USA \\ alotaib3@purdue.edu
}

\author{
Sohel Anwar, Member, \\ ASME \\ Department of Mechanical \\ Engineering \\ IUPUI, Indianapolis, IN, USA \\ soanwar@iupui.edu
}

\author{
M. Terry Loghmani \\ School of Health and \\ Rehabilitation Sciences \\ IUPUI, Indianapolis, IN, USA \\ mloghman@iu.edu
}

This is the author's manuscript of the article published in final edited form as:

Alotaibi, A. M., Anwar, S., \& Loghmani, M. T. (2017). A Force Sensing Instrument Assisted Soft Tissue Mobilization Device, V001T08A001. https://doi.org/10.1115/DSCC2017-5040 


\section{ABSTRACT}

Instrument assisted soft tissue mobilization (IASTM) is a form of massage using rigid manufactured or cast devices. The delivered force, which is a critical parameter in massage during IASTM, has not been measured or standardized for most clinical practices. There is a strong need to characterize the delivered force to a patient. This paper proposes a novel mechatronic design for a specific instrument to apply localized pressure which is a frequently used tool to clinically deliver localize pressure to treat soft tissue. The design is based on 1-D compression load cells, where 4-load cells are used to measure the force components in three-dimensional space. Here the proposed design of the mechatronic IASTM tool is modeled, analyzed, and simulated as a mechanical structure with simplifying assumptions on the elastic behavior of the skin under a certain amount of force conditions. A finite element model of a human arm is simulated to show the relationship between the applied forces, stress and strain on the skin, and force measurements to improve the design. The relation between device's tip and the modeled arm was assumed to be frictional contact similar to the real IASTM practice.

\section{INTRODUCTION}

Physical therapy has been used to help people to relieve their pains and stresses for thousands of years. The physical therapy practice has different styles and methods, which have been improved and modified to meet patients' satisfaction and wellbeing. Instrument assisted soft tissue mobilization (IASTM) is a massage technique that uses solid tools to enhance the

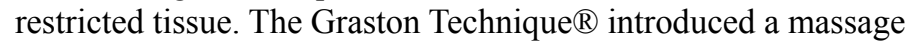
methodology based on IASTM using six different tools for different tasks and functions, illustrated in (Fig1).

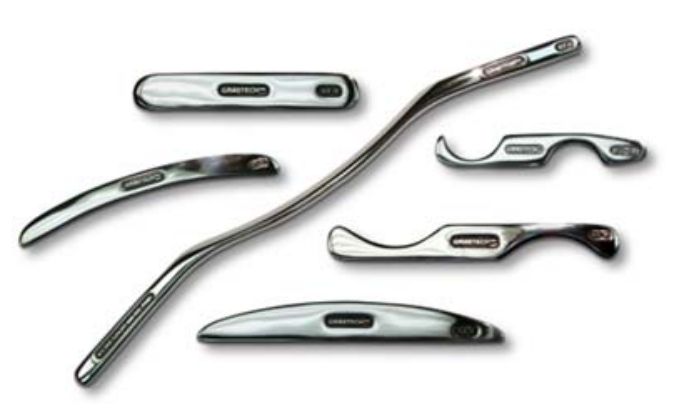

Figure 1: Graston Technique ${ }^{\circledR}$ Instrument Set [13].

Massage therapy has been used widely for decades; however, the lack of force quantification, which can potentially computed by a clinician, has affected the development of optimal dosing during an IASTM process and the understanding of its underlying biological mechanisms [1-3]. The IASTM has offered interesting results with different conditions and tissues
[4-11]. These studies showed that the force applied by the therapist is a critical parameter in the IASTM, and it should be quantified and measured accurately for research purposes as well as clinical applications.

The Graston Technique (GT) was introduced to the world of physical rehabilitation by an athlete who suffered a debilitating knee injury during a water skiing accident. Left with resultant scar tissue from the injury that caused pain and restriction of motion and function in the affected tissues [12], he created various tools to treat the soft tissue surrounding his knee using his knowledge in machining. In 1994, TherapyCare Resources Inc., the founding company of the Graston Technique $\AA$, was established in Indianapolis, IN [12]. GT has been recommended for use in the treatment of soft tissue injury (e.g. tendinopathies, trigger-points, hypertonicity and myofascial pain)[13].

Instrument-assisted soft tissue mobilization (IASTM or ISTM) technique has been utilized in treatment of soft tissue dysfunction. The method focuses on a controlled force to an area of excessive scar tissue or fibrosis. This has been found to stimulate repair and reorganization of affected tissue [14]. In one study, GT treatment was found to improve shoulder motion in overhead athletes (softball, baseball, or volleyball). Heinecke, Thuesen and Stow [15], GT treatment was found to better facilitate treatment of soft tissue movement limitations, when compared with dynamic stretching and strengthening protocols.

In another study, Laudner, et.al [16], argued that limited glenohumeral $(\mathrm{GH})$ range of motion (ROM) occurs during the deceleration phase of overhead throwing due to the repetitive rotational and distractive forces exerted on the posterior shoulder, which can lead to shoulder injuries. IASTM, such as the Graston Technique, was found to be effective for various shoulder injuries and disorders.

In a case study by Loghmani [17], of a 55-year-old man who had injured the proximal interphalangeal joint of the left indexfinger, physical measures were improved, including an immediate gain in finger range of motion with IASTM alone. However, it was seen that manual therapy approaches integrating IASTM could provide an effective conservative treatment strategy for patients with finger-hand conditions in the performing arts and other patient populations.

As a conservative approach, eccentric strengthening exercises have been used for the treatment of Achilles tendinopathy. The recommended treatment period for this approach is 12 weeks. Phipps et. al. [18], demonstrate the potential effectiveness of IASTM as a manual therapy approach for the treatment of tendon disorders. They show the potential to yield positive outcomes in a reduced treatment time. However, it was seen that the treatment regimen included exercise; therefore, the effect of IASTM was not isolated. However, despite this limitation, the treatment combination yielded positive outcomes in relatively fewer visits. Looney, et al. [8] also carried out studies to demonstrate that patients with plantar fasciitis treated with GT and a home stretching program experienced clinically meaningful improvements.

Arthrofibrosis of the knee is a surgical complication that can limit range of motion, inhibit muscle activity, and decrease 
patient function. In studies by Black [18], GT was used as a rehabilitative course in arthrofibrotic limitations. Clear improvement in range of motion and quadriceps activity and function was noted.

Several human and animal studies have attempted to measure the pressure delivered during soft tissue manipulation using different strategies.. An earlier human study by Hsin-Min Lee et al. [19] investigated the effect of transferred friction massage (TFM) on flexor carpi radialis (FCR) motoneuron (MN) pool excitability. They built an electronic system to evaluate the massage rate, momentary pressure and total cumulative pressure. Their system is based on an ultrathin flexible pressure sensor (ConTacts C500) and it is fixed on a thumb of the physician and insulated by plastic glove. However, this system could potentially provide an inaccurate measurement for clinical use for several reasons, e.g. sensor slippage causing aberrant motion and force detection. Also, any electrical failure in the system can cause harm either to physician or patient since one of its components is directly in contact with the therapist's hand. And different therapists have different thumb sizes and softness, which might affect the force measurements.

Recently, an animal study by Qian Wang et al. [20] has developed an automated device that can generate a certain amount of force using a feedback loop. Force can be applied either with compression or transverse force profiles; however, transverse force is not used as a feedback. The device consists of a base, where small animal (rats and rabbits) are held during application, and two movement axes to apply force in the horizontal $(\mathrm{X})$ and vertical $(\mathrm{Z})$ directions. Two-axis force sensors, which are based on piezoresistance, are mounted at the bottom end of the Z-axis, and can measure both compression and tensile forces in the $\mathrm{X}$ and $\mathrm{Z}$ directions. Different stainless steel tips, which can be fixed on the two-axis force sensors, have been manufactured according to different tissue size. This bulky equipment has provided a useful method to quantify the force delivered to the subject; however, this device is impractical for clinical usage because of its constraints, and neglecting the transverse force will result in inaccurate resultant force readings.

Similarly, another animal study by Hansong Zeng et al. [20], constructed a vertical automated compression device, which used a pneumatic system to apply a certain amount of force on a rabbit. A linear motion control system was used to control the generated force, and a force sensor (Pasco Inc., U.S.) provided the feedback to the device. But this device conflicted with the maneuverability, repeatability and feasibility required in the clinical practice.

In this paper, a proposed design of a mechatronic IASTM device system for localized application of pressure, similar to the treatment tip of GT3, as shown in (Fig 2), will be presented, analyzed, constructed, and evaluated. The design uses 1D compression load cells, where four 1D load cells are used to measure the three force components in the $3 \mathrm{D}$ space. The $3 \mathrm{D}$ printing technology has been used to fabricate and assemble the device. The primary objective of this work is to design, build, and test an accurate force measurement system for IASTM tool and provide other important parameters, such as the tool orientation angles, stroke frequency, and a full monitoring system using a suitable platform for clinical and research use. The design concept is intended to enable expansion to other shaped treatment tips for dispersive pressure and use on different shaped body parts.

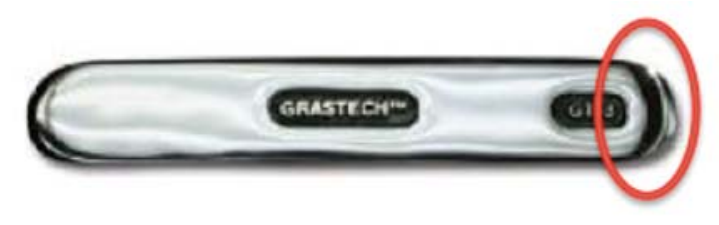

Figurer 2: GT-3 Treatment Tip [13].

\section{DESIGN OF THE PROPOSED IASTM DEVICE}

\section{Design Requirements}

To design the mechatronic IASTM device, different parameters should be considered in the design stages. From a safety perspective, the new device must run at relatively low voltage to reduce the risk of electric shock. The device should be compact, lightweight, and portable. The new device require measuring forces within 0-100 N, device orientation angles, treatment time, and stroke frequency during a session. It is preferred that the new designs be adaptable to fit different IASTM devices. In addition, they have to be durable and reusable because of their frequent usage in clinics, and they must be available at reasonable prices.

\section{Electronic Component Selection}

After considering all design requirements, extensive research was conducted to reach the optimal design that could meet the requirements stated in the previous section. The IMUduino microcontroller [21] was selected to measure the angles and stroke frequency using its Gyro, a 3-Axis Digital Compass IC, and an Accelerometer. The IMUduino board had a small form factor $(39.8 \mathrm{~mm} \mathrm{X} 15.72 \mathrm{~mm})$ which helped in reducing the device size.

An extensive and wide-ranging search on force sensors was performed to select the appropriate force sensor for the new IASTM tool design. The selected force sensor was the smallest compression load cell (FC-08) [22], which was a compression type load cell produced by Forsentek Co., Limited, as shown in (Fig 3). It can measure up to $20 \mathrm{~kg}$ of force acting vertically on its nob with a diameter and height of $8 \mathrm{~mm}$ and $5 \mathrm{~mm}$, respectively. The output of the load cell were amplified and filtered using a signal conditioning unit.

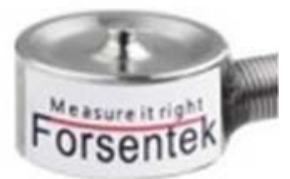

Figure 3: The Smallest Compression Load Cell (FC-08) [23]. 


\section{The IASTM Device Design}

After all electronics and sensor have been selected, the new designs of the IASTM tool were created using Creo Parametric 2.0 CAD software. The model was constructed based on the compression load cell, as shown in Fig. 4. This device consists of four parts: tip, frame, back cover, and keyways. The tip was designed to be similar to the GT-3 tip, so it would have the same precision for targeting soft tissues. A measurement cavity was design to fit four compression load cells (Fig. 5). A back cavity was designed to fit all electronic component sizes needed for the device. A back cover was used to seal and insulate the electronics inside the cavity. The cross section of the frame was narrowed for finger placements in consideration of the overall diameter and sensor placements.

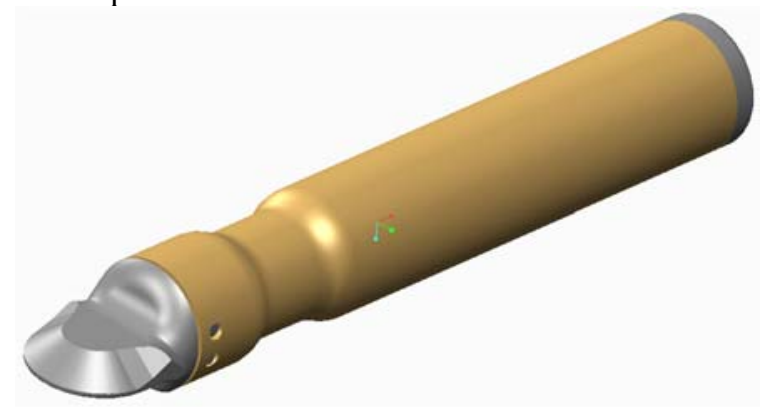

Figure 4: Device Based on the Compression Load Cell.

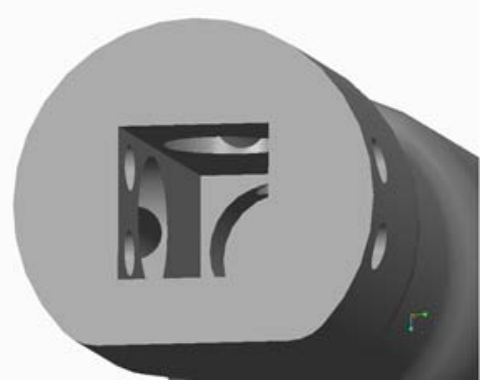

Figure 5: Sensor Placements for the Compression Load Cell Model.

In terms of force measurements, this design used combinations of the compression load cell to measure the three resultant force components in three-dimensional space. The orientation angles of the IASTM device, which had an effect on the force measurements, were considered in the new device design stage. The expected orientation angle between the IASTM device and skin generally varies between 20 and 70 degrees in a typical treatment; this is based on the $\mathrm{X}-\mathrm{Y}$ plane, with free rotation about the Z-axis (normal to skin surface). As shown in (Fig 6), the compression load cell design consisted of four load cells, which was based on the force analysis of the measured forces.

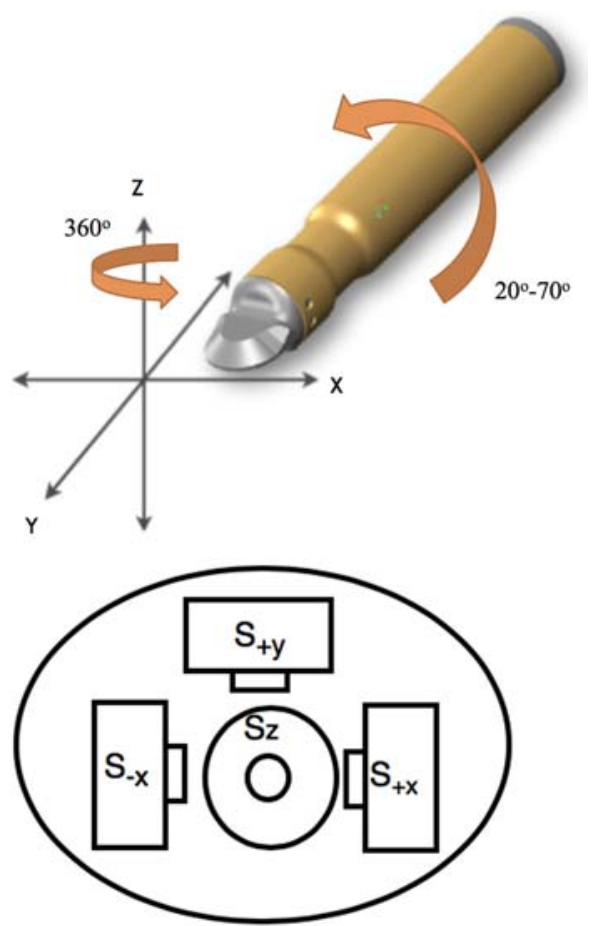

Figure 6: Mechatronic IASTM Device Orientation Angles and Sensors Placement.

According to the orientation constraints, there were three expected movements, each of which produced three different measurements of force. As shown in (Fig. 6), various load cells were positioned around the measurement cavity based on force factorization. First, $\mathrm{S}_{\mathrm{z}^{+}}$and $\mathrm{S}_{\mathrm{y}^{+}}$load cells measure force components where the force was applied in Y-Z plane at the tip of the IASTM device. Second, when the force was applied with an angle between 0 and 89 degrees, three force components were measured by the $\mathrm{S}_{\mathrm{z}^{+}}, \mathrm{S}_{\mathrm{x}-}$ and $\mathrm{S}_{\mathrm{y}^{+}}$load cells. Third, when the force was applied with an angle between 91 and 180 degrees, three force components were measured by the $\mathrm{S}_{\mathrm{z}^{+}}, \mathrm{S}_{\mathrm{x}^{+}}$and $\mathrm{S}_{\mathrm{y}+}$ load cells. As a result, this force analysis confirmed that there was no need for the fifth load cell since there was no force component in the direction of $-\mathrm{Z}$ and $-\mathrm{Y}$; this would lead to reduced cost of the compression load cell device.

As shown in (Fig. 7), the measurement mechanism of the compression load cell device was based on forces measured by a well-placed four compression load cells and a subsequent transformation to an appropriate coordinate system. Three tiny wiring canals were used to connect the wires from the load cell compartment to the microcontroller in the electronics cavity. This design included two keyway pins to lock the tip to the main frame with $3 \mathrm{~mm}$ clearance to allow force transmission.

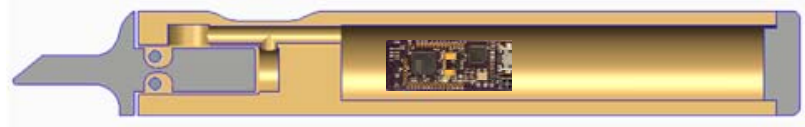

Figure 7: Full Section for the Compression Load Cell Device. 


\section{ANALYSIS OF THE PROPOSED DEVICE DESIGN}

\section{Skin and Tissue Modeling}

For the purposes of this study, the human tissues and layers were modeled in Creo Parametric 2.0 as a $100-\mathrm{mm}^{3}$ box with four curved edges to be similar to an arm, as shown in (Fig 8). A cylindrical hollow of $30 \mathrm{~mm}$ diameter was designed for bone placement. The skin model was imported to ANSYS Workbench R15.0 to perform the simulation.

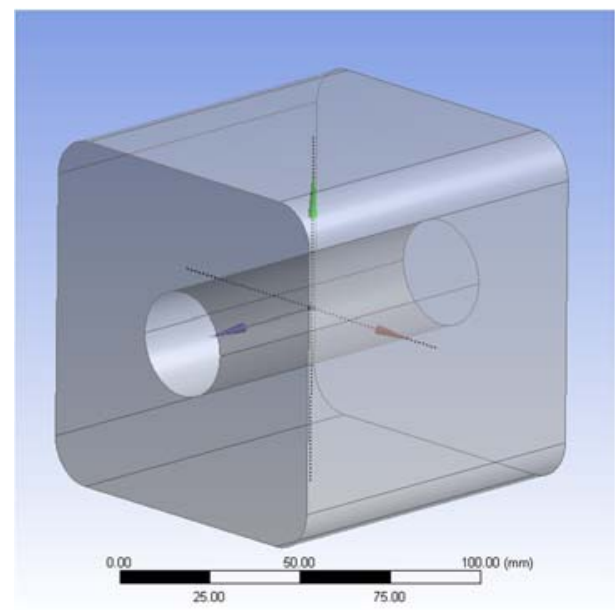

Figure 8: Human Arm Model in ANSYS.

Human tissue is a very complex structure in the human body which has four main layers: skin, subcutaneous adipose tissue, muscle, and bone, each of which has different mechanical properties. Agache al. [23] has presented these mechanical properties and Young's modulus of human skin in Vivo, and showed that Young's modulus varies between $0.42 \mathrm{MPa}$ and 0.85 $\mathrm{MPa}$. According to the Physics Hyper textbook [24], skin density was shown to be about $1050 \mathrm{Kgm}^{-3}$. In a study of characterization of the mechanical properties of skin by inverse analysis combined with the indentation test [25], Poisson's Ratio was estimated to be 0.48 using the indentation test. The ultimate tensile strength (UTS) has been determined to be between 5.7 and 12.6 MPa [26], and has been selected to be the UTS of all tissue layers, as shown in Table 1.

Table 1 Mechanical Properties of Human Skin.

\begin{tabular}{|c|c|}
\hline Parameter & Value \\
\hline Element Type & $\begin{array}{c}\text { 3D Solid Quadrilateral } \\
\text { Isotropic }\end{array}$ \\
\hline Density & $1050 \mathrm{~kg} / \mathrm{m}^{\wedge} 3$ \\
\hline $\begin{array}{c}\text { Young's } \\
\text { Modulus }\end{array}$ & $0.82 \mathrm{MPa}$ \\
\hline Poisson's Ratio & 0.48 \\
\hline UTS & $12.6 \mathrm{MPa}$ \\
\hline
\end{tabular}

As shown in Fig 9, a finite element mesh was generated for the human skin model, which holds the skin's mechanical properties, in order to compute the resultant stress-strain at each node on the skin. The more mesh the model had, the more accurate the result became. However, increasing the mesh size resulted in increasing the solution time. As a result, a mesh refinement was performed on the skin surface, since the purpose of this study was to show skin reaction to the applied forces.

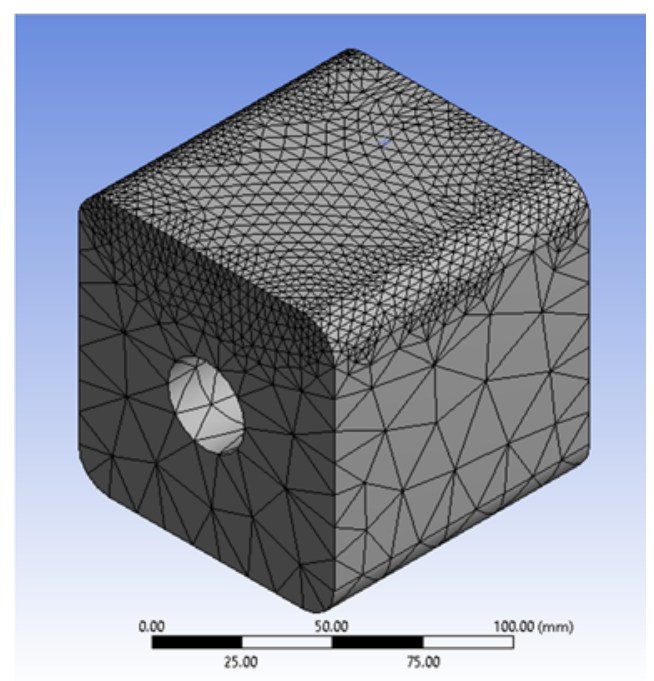

Figure 9: Skin Meshing.

\section{Proposed Device Modeling}

The device, which was based on four compression load cells, was imported to ANSYS workbench R15.0 to perform the simulation, as shown in Fig. 10. As shown in Table 2, stainless steel was selected to be the material for both the tip and tail of the IASTM device. Different assumptions were utilized to simplify the analysis; the back cover was welded to the device tail. In addition, the four compression load cells were embedded into the device's front end of the tail, where the device's front end and the four load cells were part of the tail made of stainless steel, as shown in Fig 11.

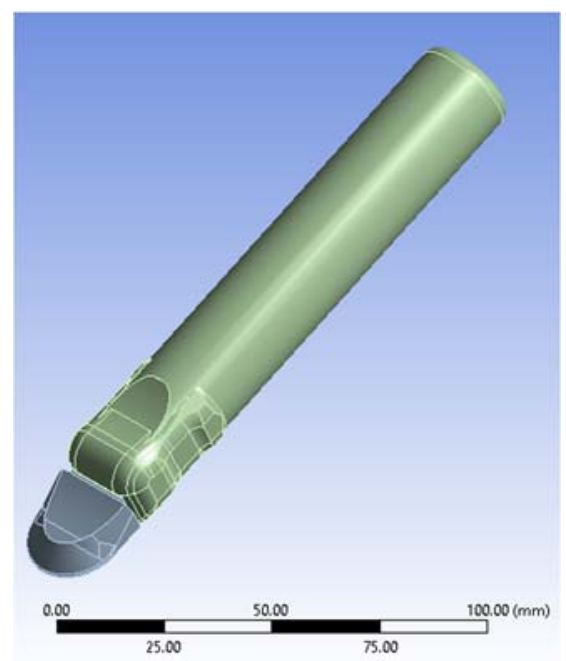

Figure 10: Compression IASTM Load Cell Device in ANSYS. 
Table 2. Mechanical Properties of The Compression IASTM Load Cell Device.

\begin{tabular}{|l|l|}
\hline Parameter & Value \\
\hline Density & $7750 \mathrm{~kg} / \mathrm{m}^{\wedge} 3$ \\
\hline Young's Modulus & $1.93 \times 10^{5} \mathrm{MPa}$ \\
\hline Poisson's Ratio & 0.31 \\
\hline UTS & $586 \mathrm{MPa}$ \\
\hline
\end{tabular}

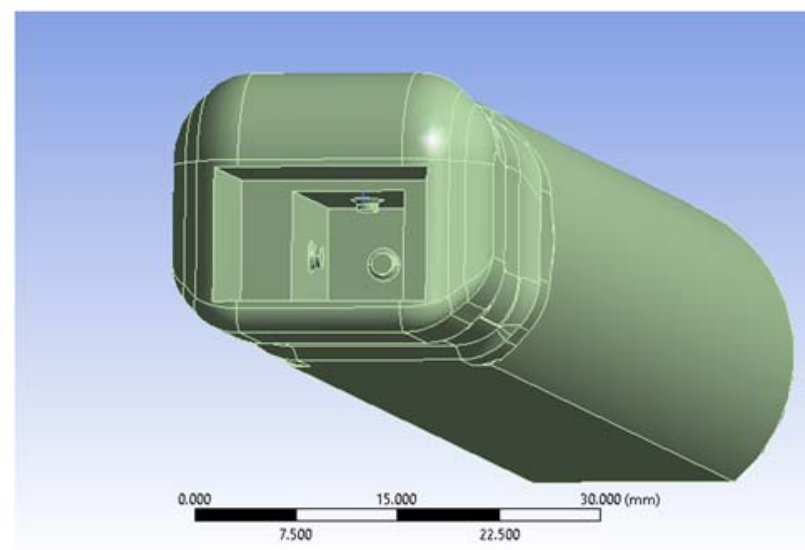

Figure 11: Compression Load Cell Embedded into The Device Tail.

Meshing was generated for both the tip and tail models, as shown in Fig 12. Since the purpose of this analysis was to evaluate stress and the applied force on the skin with respect to force measurement, the load cells tips' mesh was refined to obtain accurate force analysis, as shown in Fig 13.

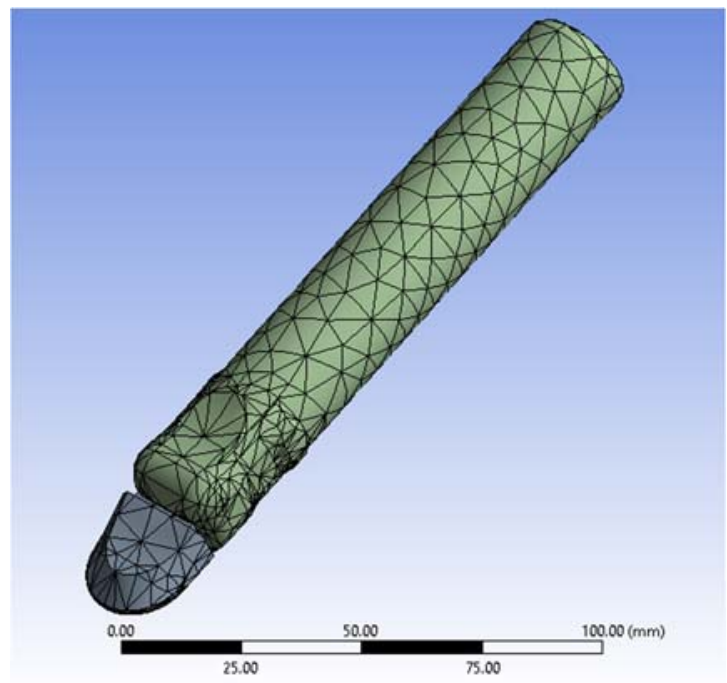

Figure 12: Meshed Load Cell Device.

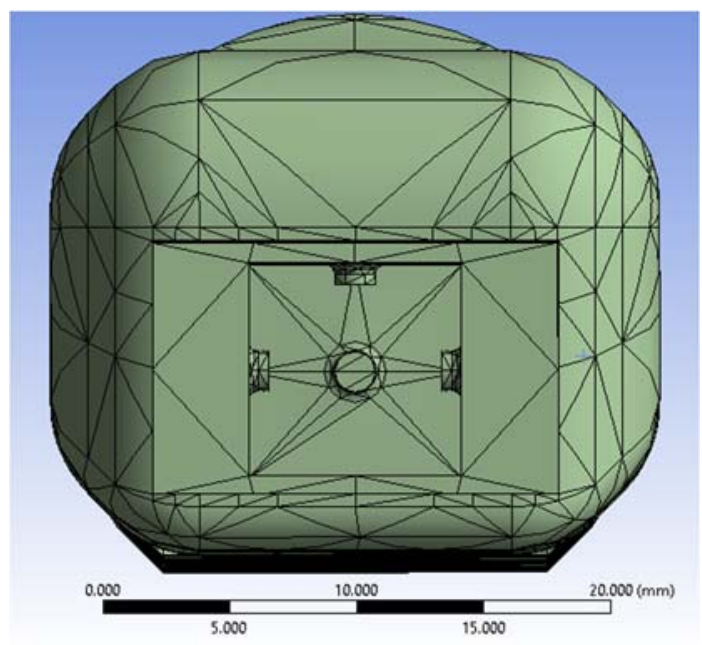

Figure 13: Meshed Load Cell Tail.

\section{Simulation Setup}

After the compression load cell device and the skin model were imported to the ANSYS Workbench, connections and the static structural setting had to be defined to conduct the simulation. The finite element analysis of the 1D compression load cell device has been simulated and investigated. The mechanical connection between the device's tip and skin surface was assumed to be frictional.

The device's tip was linked to the tail with small tolerance, so force could be transferred from the device's tip to the four compression load cells when force was applied to the patient's skin. As a result, the connection between the tip and the tail was assumed to be a bonded connection, where nine faces on both parts were defined to be the connection areas, as shown in Fig 14.

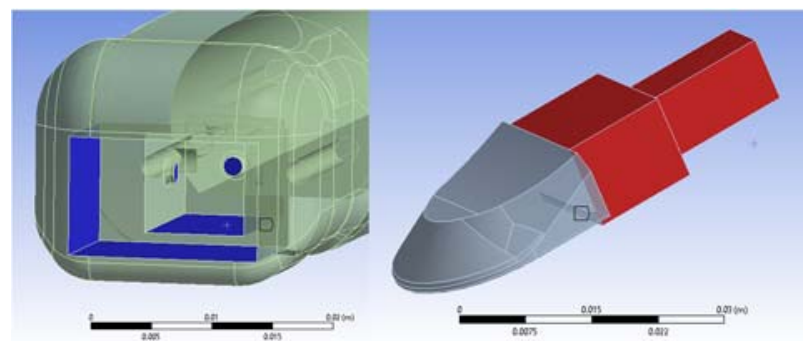

Figure 14: Device Tail and Tip Bonded Connections.

In the IASTM treatment, tools interact with human skin in different areas, and most of these tools, which are used in physical therapy clinics, are made of stainless steel. The contact between the polished stainless steel and skin is a frictional contact, even when gel is used to minimize the friction. As a result, the connection between skin and the device tip was determined to be a frictional connection. The frictional coefficient plays an important role in defining the relationship between two materials and normal force, and the frictional coefficient between skin and stainless steel has been found to be one [27]. The contact areas were defined as four faces on the 
device tip and the upper area of the arm model, as shown in Fig 15. The Augmented Lagrange formulation was used to define the contact area and prevent interaction between two bodies using equation (1), where $\lambda$ made the solution less sensitive to contact stiffness [28].

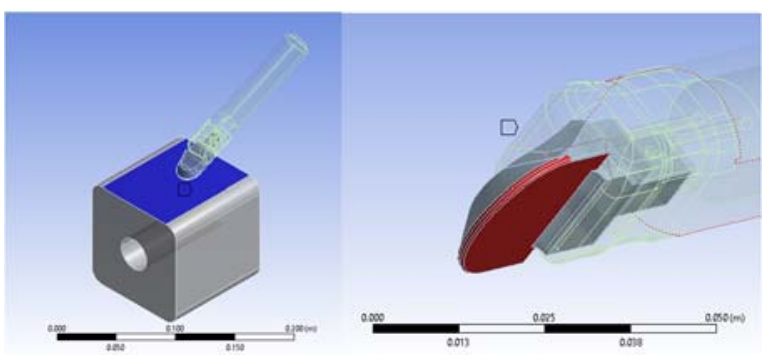

Figure 15: Device Tip and Skin Frictional Contact Areas.

$$
\mathrm{F}_{\text {normal }}=\mathrm{k}_{\text {normal }} \mathrm{x}_{\text {penetration }}+\lambda
$$

After the connections were defined, the contact initial information was generated and investigated using contact tools. The table shows all connections, geometric gaps, and penetration, and the resulting pinballs' radii, which provide an efficient contact calculation by differentiating the far and near contact regions while identifying the expected contact elements [6].

The static structural and boundary conditions were defined after meshing was performed and the contact information was generated. The analysis time was set for 6.3 seconds, and the number of steps was 12. For the nonlinear controls of the static structure, the unsymmetrical Newton Raphson option was selected to help with convergence of the solution. In the real practice of IASTM, the device was moved with certain acceleration on a skin surface. Therefore, the device acceleration was assumed to be $0.5 \mathrm{~mm} / \mathrm{s}^{2}$ in a direction parallel to the skin surface (Z- axis), as shown in Fig 16.

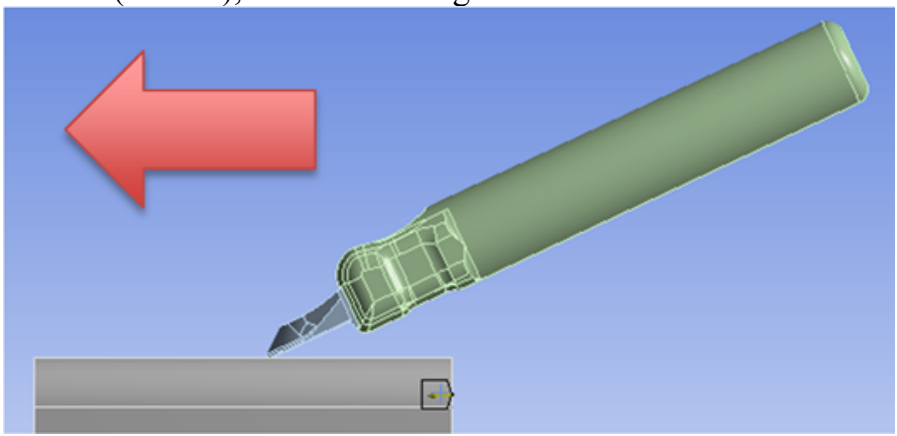

Figure 16: Direction of Device's Acceleration.

The displacement constraint was set as follows: the bottom surface of the device was selected to apply the displacement condition, as shown in Fig 17. The device was set free to move against the skin, which was represented by the $\mathrm{Z}$ direction in the device coordinate system. Similarly, the device was set to move across and parallel to the skin with an acceleration of $0.5 \mathrm{~mm} / \mathrm{s}^{2}$.
But the device was not allowed to have sideways movements, which means it couldn't move in X direction.

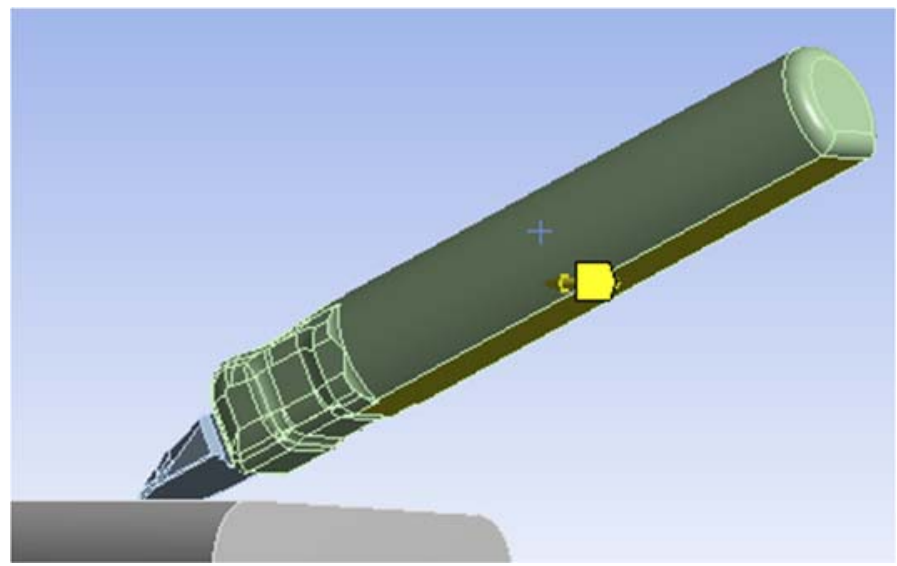

Figure 17: Device Displacement Constraint Areas.

IASTM has different treatment positions and methodologies, where force is applied to different parts of the device. For the new IASTM device, the force could be applied to device either on the tool neck or on the back cover, as shown in Figures 18 and 19. In both cases, the same pressure amount would be delivered to the skin. In this FEA, a compression force was chosen to be applied gradually to an area of $207.14 \mathrm{~mm}^{2}$ on the back cover to test the IASTM under different pressures /forces and to assist with the force convergence, as shown in Table 3.

Table 3. Hand Pressure on the Back of Device in FEA.

\begin{tabular}{|c|c|c|}
\hline Steps & Time [s] & Pressure [MPa] \\
\hline 1 & 0 & 0 \\
\cline { 2 - 2 } & 1 & \multirow{2}{*}{0.1} \\
\hline 2 & 2 & \\
\hline 3 & 3 & \multirow{2}{*}{0} \\
\hline 4 & 4 & 0.2 \\
\hline 5 & 5 & \multirow{2}{*}{} \\
\hline 6 & 6 & \multirow{2}{*}{0.25} \\
\hline 7 & 7 & \\
\hline
\end{tabular}




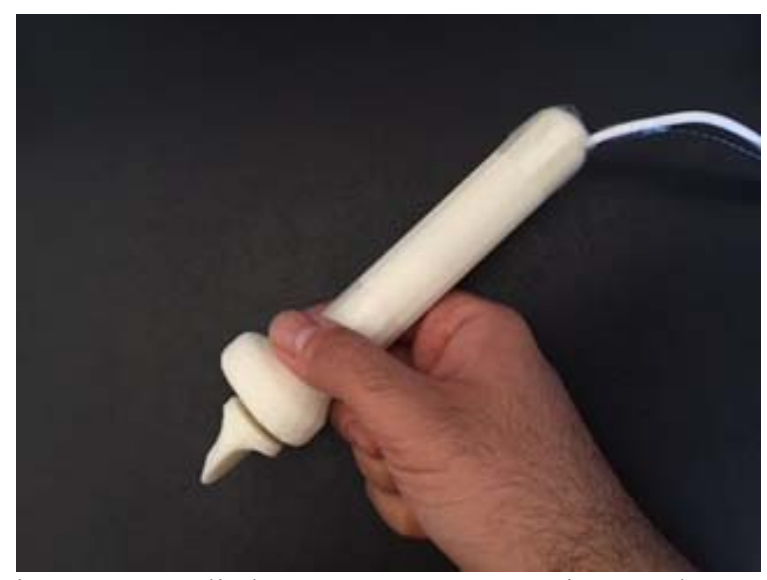

Figure 18: Applied Force to IASTM Device on The Tool Neck.

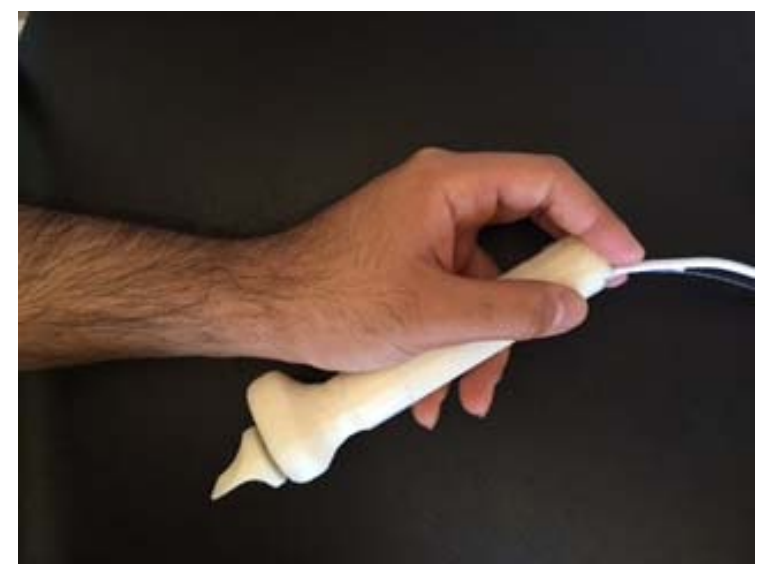

Figure 19: Applied Force to IASTM Device on the Back Cover.

\section{SIMULATION RESULTS}

After all the IASTM device simulation's parameters were defined, the simulation was successfully solved to compute the desired stresses and strains on different components, which resulted from the applied hand force by a therapist, using ANSYS Workbench R15.0. The following subsections explore the relationship between stress and deformation on the skin, which resulted from hand pressure measured by the load cell's tips.

\section{Simulated Skin Results}

Von Mises Stress (Equivalent Stress) and Maximum Principal Stress were generated to determine the relationship between the hand pressure and the stresses on the skin. These methods are used widely to detect the failure criteria of different material under certain forces. As shown in Fig 20, the relationship between the Von Mises Stress (Equivalent Stress) and hand pressure was produced using the ANSYS. It's clear that when the hand pressure increased, the maximum and minimum Equivalent Stress also increased. In terms of maximum Equivalent Stress, the maximum value was recorded after the hand pressure was increased to $0.20 \mathrm{MPa}$, at 2.49 seconds, as shown in Fig 21. The minimum value was recorded at the beginning of the practice, at 0.10 seconds, when the device just touched the skin with a pressure of $0.0281 \mathrm{MPa}$.

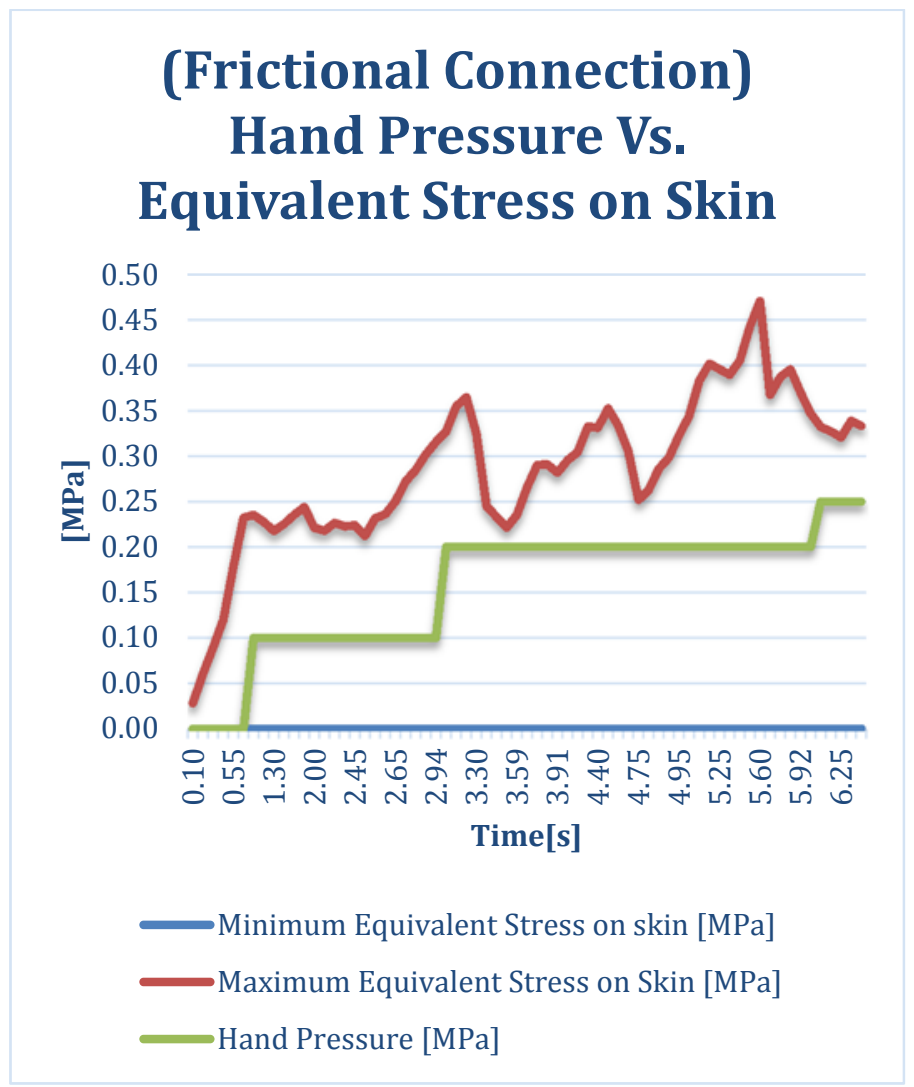

Figure 20: Hand Pressure vs. Equivalent Stress on Skin (Frictional Connection).

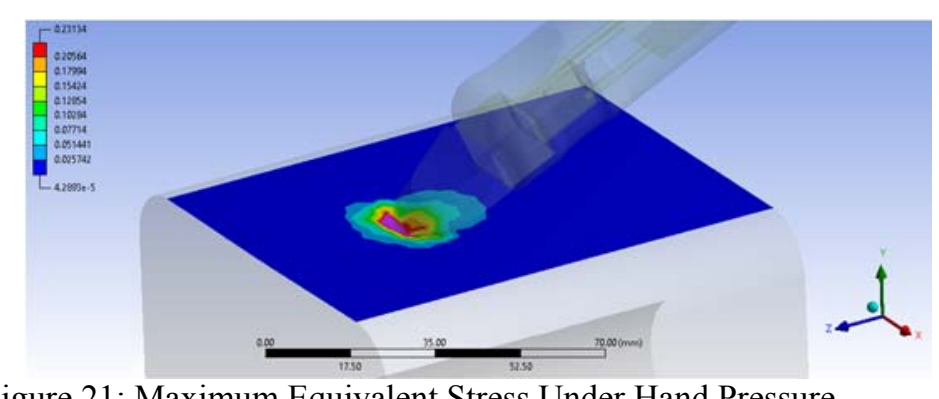

Figure 21: Maximum Equivalent Stress Under Hand Pressure of $0.20 \mathrm{MPa}$ (Frictional Connection).

The relationship between the minimum and maximum readings for the Maximum Principal Stress was generated, as shown in Fig 22. The maximum value of the Maximum Principal Stress represents the tension stress on skin, which increases when the hand pressure increases. In addition, the compression stress (minimum values) increases when hand pressure is applied, too. Although the compression stress on skin is slightly higher than the tension stress, which was recorded when hand pressure increased to $0.25 \mathrm{MPa}$, as shown in Fig 23. 


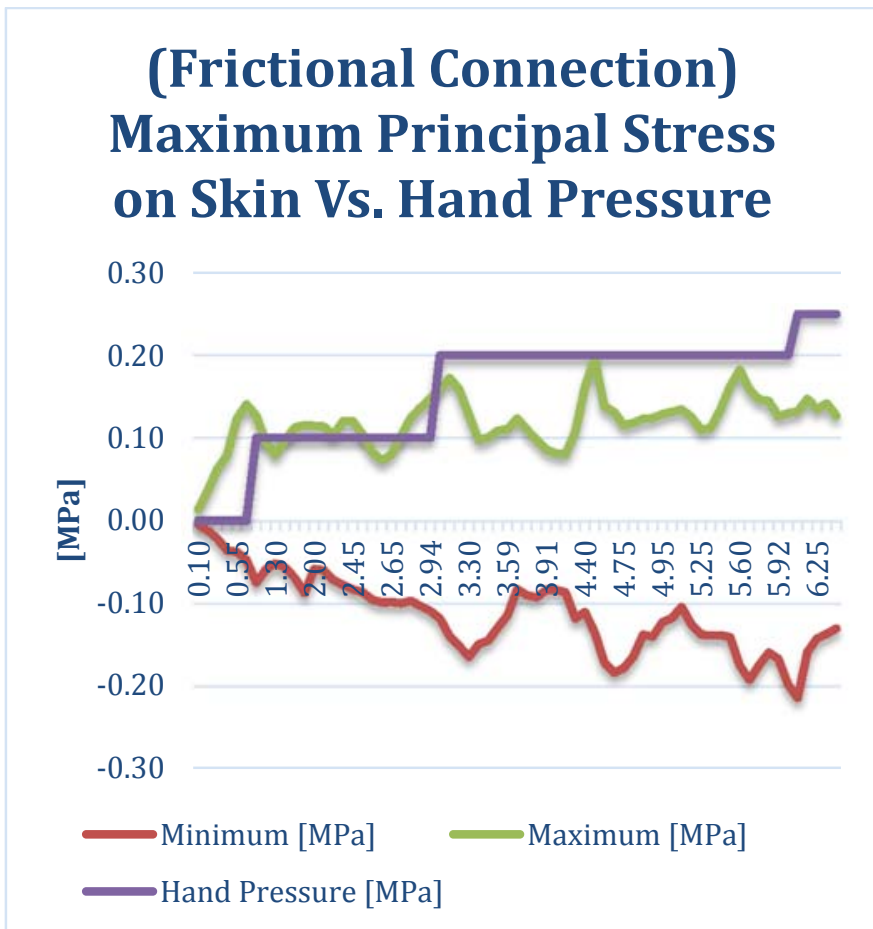

Figure 22: Maximum Principal Stress on Skin vs. Hand Pressure (Frictional Connection).

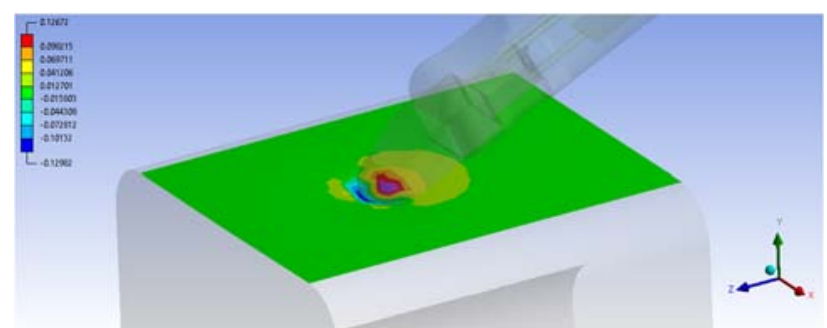

Figure 23 Maximum Value of the Maximum Principal Stress Under Hand Pressure of 0.25 MPa (Frictional Connection).

Skin/tissue deformation was an important factor in IASTM process in order to ensure the optimal treatment of the restricted tissues. As shown in Fig 24, the maximum and minimum deformation values reached their maximum after the hand pressure increased to $0.25 \mathrm{MPa}$ at 6.2 second with $4.0012 \mathrm{~mm}$ and $0.18247 \mathrm{~mm}$, respectively. To visualize the maximum total deformation, a photograph has been taken at that moment, as shown in Figure 25.

\section{(Frictional Connection) Skin Total Deformation}

10.00

1.00

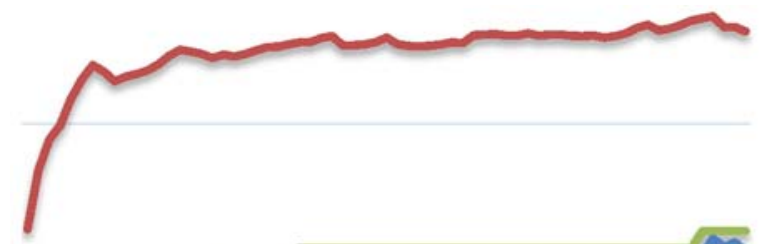

0.10

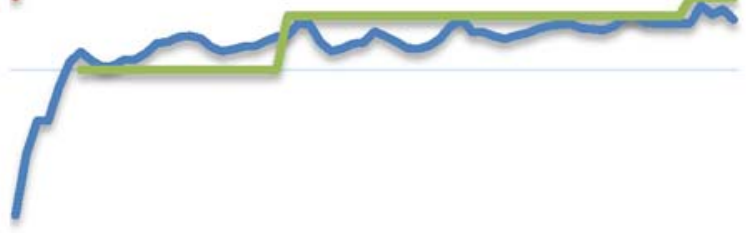

0.01 응 总 Time [Sec]

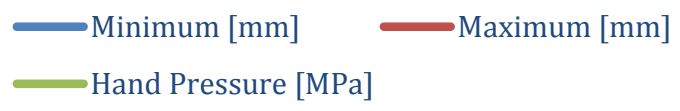

Figure 24: Skin Total Deformation (Frictional Connection).

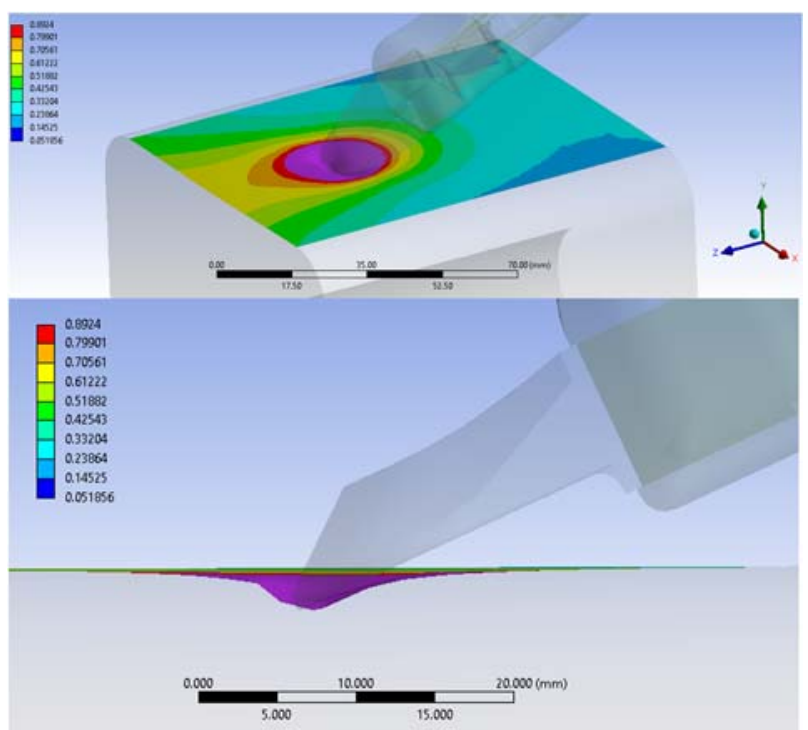

Figure 25 Maximum Total Deformation (4.0012 mm) Under Hand Pressure 0.25 MPa (Frictional Connection).

Force Simulation Results for the Device

The force measurements have been investigated when the IASTM device interacted with the patient's arm model at an angle of 20 degrees in ANSYS Workbench, to show the force/stress levels at the load cell tips $\left(\right.$ Area $\left.=2 \mathrm{~mm}^{2}\right)$ in relation 
to the therapist's hand force. As shown in Fig 26, the maximum stress on the load cells measurement has been exported, where stress measurements have been recorded on each load cell's tip. The maximum stress measurements by $\mathrm{F}_{+\mathrm{y}}$ and $\mathrm{F}_{\mathrm{Z}}$ recorded a higher stress than the stresses on the $\mathrm{X}$ axis load cells, because the device is rotated only around the pitch angle of 20 degrees and that agrees with the vector analysis that has been discussed before. The maximum stress measured by $\mathrm{F}_{+y}$ was relatively smaller than the measured stress in $\mathrm{F}_{\mathrm{Z}}$ until the hand pressure increased to $0.20 \mathrm{MPa}$ and the skin deformed $2.8566 \mathrm{~mm}$. As a result, $F_{+y}$ load cell will measure a slightly higher value than $F_{Z}$ when the hand pressure and skin deformation increases.

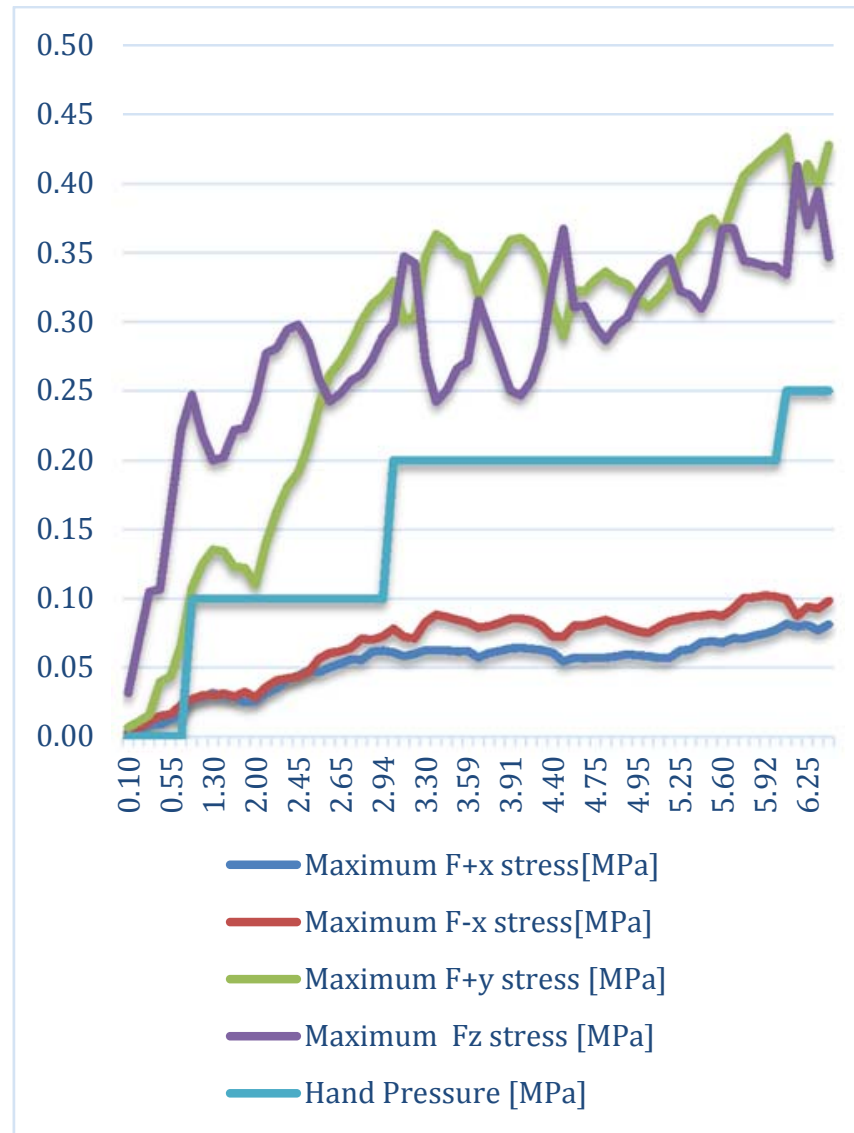

Figure 26: Maximum Four Load Cells' Stress Distribution vs. Hand Pressure (Frictional Connection).

On the other hand, the minimum stresses recorded in the directions $\mathrm{F}_{+\mathrm{y}}$ and $\mathrm{F}_{\mathrm{Z}}$ were large after increasing the hand pressure to $0.20 \mathrm{MPa}$ with resulting skin deformation of 2.8566 $\mathrm{mm}$, as shown in Fig 27. However, stress measurement in the Xaxis was still low but not higher than the maximum values. The relation between the maximum load cells measurements and equivalent stresses was investigated, as shown in Fig 28. The maximum equivalent stress on the skin, the $\mathrm{F}_{+y}$ and $\mathrm{F}_{+\mathrm{z}}$ load cells' stresses were proportional during the simulation, whereas the minimum equivalent stress on the skin was almost zero.

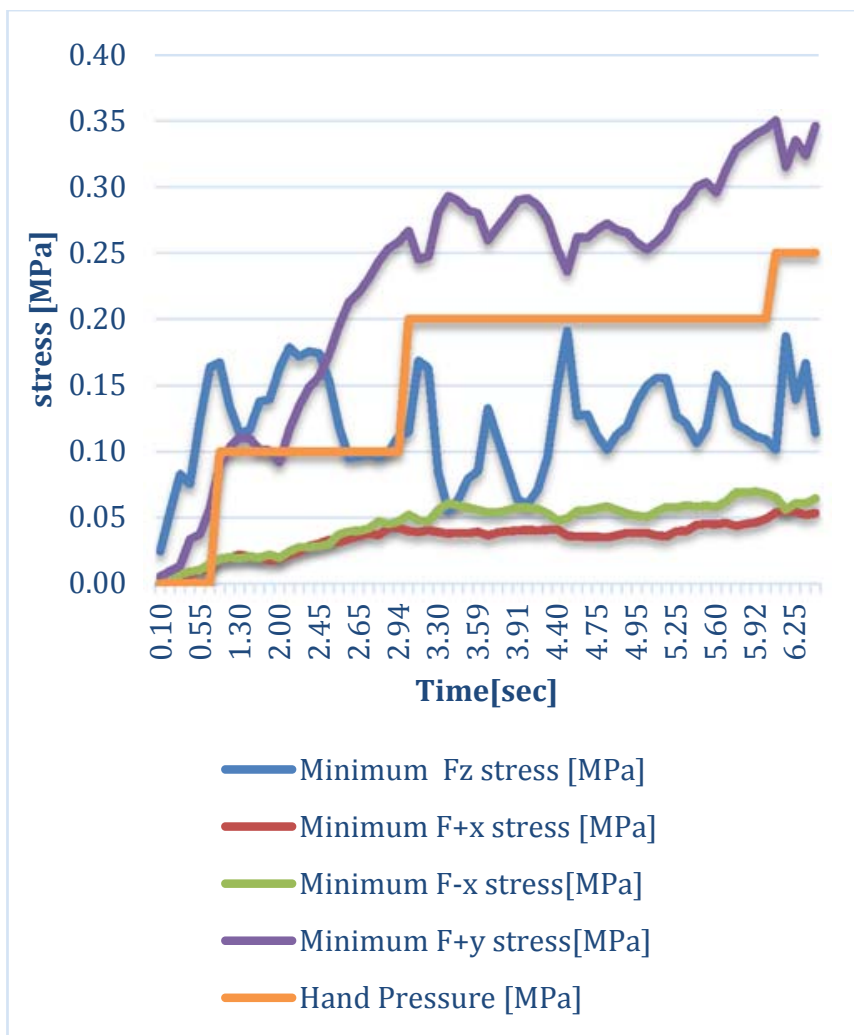

Figure 27: Minimum Four Load Cells' Stress Distribution vs. Hand Pressure (Frictional Connection).

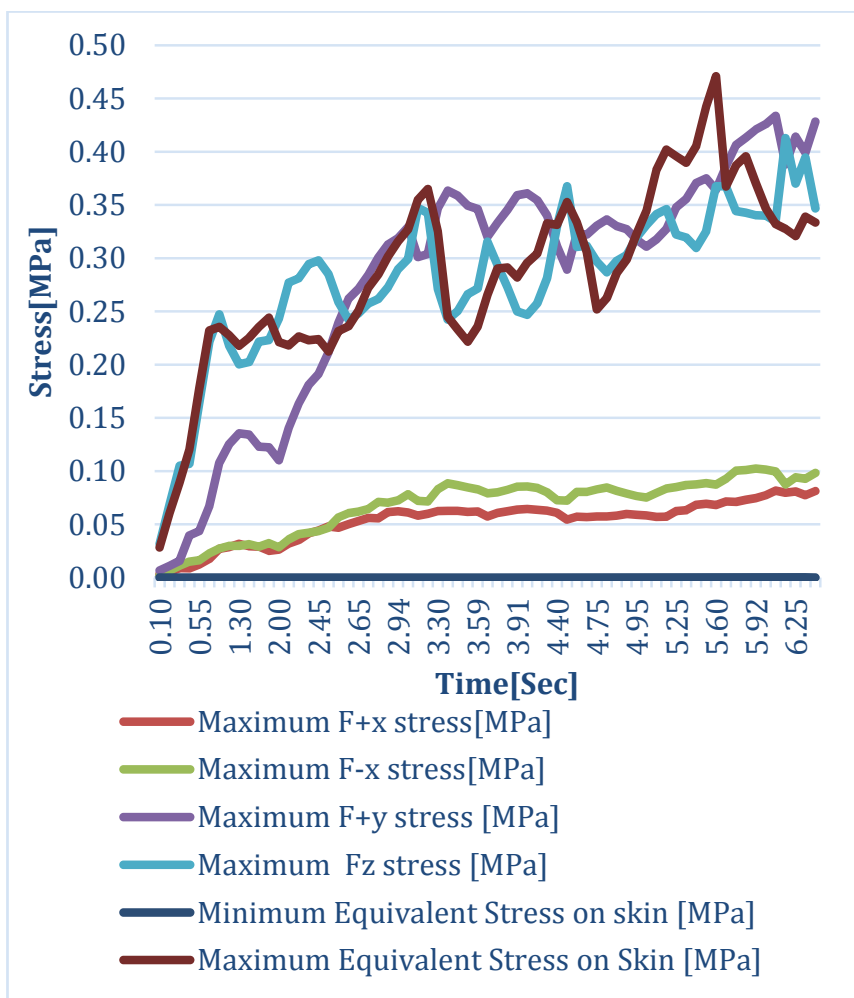

Figure 28: Minimum Four Load Cells' Stress Distribution vs. Equivalent stresses (Frictional Connection). 
Based on the stress distribution on the load cells' tips, the load cells $S_{z}$ and $S_{+y}$ have proven their functionality to measure the force components on these directions when the device move longitudinal along the skin surface (as simulated). On the other hand, the $S_{x}$ load cells would be presented with higher measurements in the sweeping stroke movement, where the device is following an arc trajectory on the skin. Lastly, the load cell $\mathrm{S}_{-\mathrm{y}}$ has been eliminated based on the force factorization that has been performed in the beginning of the study. This will reduce the final product price and the electronics needed for signal filtering.

\section{CONCLUSION}

Instrument-assisted soft tissue mobilization (IASTM) is a form of massage, i.e. soft tissue manipulation, using rigid manufactured or cast devices. The delivered force, which is a critical parameter during massage application, has not been objectively measured or standardized in a clinically relevant manner. In addition to force magnitude, the angle of force application and stroke frequency play an important role during IASTM. There is a strong need to characterize the delivered force to a patient, including the angle of treatment and stroke frequency. In this paper, a novel device was developed to deliver localized pressure to the soft tissue. The design was compression load cell based, where four load cells were used to measure the three force components in three-dimensional space. A finite element analysis using ANSYS software was created for the IASTM device to simulate IASTM practice using the GT-3 tool. Deformation and stress on the skin were measured after applying a certain amount of force with the IASTM device with an angle 20 degree. In addition, the relationship between the skin stress and the load cell measurements were investigated. Based on force factorization of the practice, four 1D compression load cells were utilized to quantity the delivered force components. This force analysis confirmed that there was no need for the fifth load cell since there was no force component in the directions of $-\mathrm{Z}$ and $-\mathrm{Y}$. This would lead to reduced cost of the future device. The load cells $S_{z}$ and $S_{+y}$ have measured the highest force components on these directions when the device moved longitudinal along the skin surface (as simulated). Higher force components on $\mathrm{X}$ axis would be measured by the $\mathrm{S}_{\mathrm{x}}$ load cells when the device movies on arch trajectory movement. The finite element analysis has proven that the proposed design can measure the delivered force to a patient using four 1D compression load cells. Besides, the proposed design has met all design requirements. As a result, the new device has established the new generation of IASTM. Further work will concentrate on investigate other scenarios such as: different angels, arch trajectory movements and bonded connection between the device's tip and skin. That will investigate the transversal measurement on $\mathrm{X}$ axis and the momentary effects on skin surface.

\section{REFERENCES}

[1] S. Kumar, K. Beaton and T. Hughes, "The effectiveness of massage therapy for the treatment of nonspecific low back pain: a systematic review of systematic reviews", International Journal of General Medicine, p. 733, 2013.

[2] J. D. Crane, D. I. Ogborn, C. Cupido, S. Melov, a. Hubbard, J. M. Bourgeois, and M. a. Tarnopolsky, "Massage therapy attenuates inflammatory signaling after exercise-induced muscle damage," Science Translational Medicine, vol. 4, no. 119, pp. 13-119, 2012.

[3] T. M. Best, S. K. Crawford, C. Haas, L. Charles, and Y. Zhao, "Transverse forces in skeletal muscle with massagelike loading in a rabbit model," BMC Complementary and Alternative Medicine, vol. 14, pp. 1-9, 2014.

[4] C. J. Davidson, L. R. Ganion, G. M. Gehlsen, B. Verhoestra, J. E. Roepke, and T. L. Sevier, "Rat tendon morphologic and functional changes resulting from soft tissue mobilization," Medicine and science in sports and exercise, vol. 29, no. 3, pp. 313-319, 1997.

[5] G. M. Gehlsen, L. R. Ganion, and R. Helfst, Fibroblast responses to variation in soft tissue mobilization pressure," Medicine and science in sports and exercise, vol. 31, no. 4, pp. 531-5, 1999.

[6] M. T. Loghmani and S. J. Warden, "Instrument-assisted cross fiber massage accelerates knee ligament healing," The journal of orthopedic and sports physical therapy, vol. 39, no. 7, pp. 506-514, 2009.

[7] M. T. Loghmani and S. J. Warden, "Instrument-assisted cross fiber massage increases tissue perfusion and alters microvascular morphology in the vicinity of healing knee ligaments," BMC Complementary and Alternative Medicine, vol. 13, p. 1, 2013.

[8] B. Looney, T. Srokose, C. Fernandez-De-Las-Peas, and J. A. Cleland, "Graston instrument soft tissue mobilization and home stretching for the management of plantar heel pain: A case series," Journal of Manipulative and Physiological Therapeutics, vol. 34, no. 2, pp. 138-142, 2011.

[9] A. J. Bayliss, F. J. Klene, E. L. Gundeck, and M. T. Loghmani, "Treatment of a patient with post-natal chronic calf pain utilizing instrument-assisted soft tissue mobilization: a case study," Journal of Manual \& Manipulative Therapy, vol. 19, no. 3, pp. 127-134, 2011.

[10] E. C. McCrea and S. Z. George, "Outcomes following augmented soft tissue mobilization for patients with knee pain: a case series," Orthopedic Physical Therapy Practice, vol. 22, no. 2, pp. 69-74, 2010.

[11] J. Burke, D. J. Buchberger, M. T. Carey-Loghmani, P. E. Dougherty, D. S. Greco, and J. D. Dishman, “A pilot study comparing two manual therapy interventions for carpal tunnel syndrome," Journal of Manipulative and Physiological Therapeutics, vol. 30, no. 1, pp. 50-61, 2007.

[12] G. TECHNIQUE, "History of graston technique," 2016. [Online].

Available: 
http://www.grastontechnique.com/history. [Accessed: 21Feb- 2016].

[13] G. TECHNIQUE, IGraston technique advantages," 2016. [Online]. Available: http://www.grastontechnique.com/home. [Accessed: 21Feb- 2016].

[14] R. L. Phipps, S. R. Carney, M. T. Loghmani, and A. J. Bayliss, "An innovative manual therapy approach for the treatment of patients with Achilles tendinopathy: A case series," Journal of orthopaedic and sports physical therapy, 2011.

[15] M. L. Heinecke, S. T. Thuesen, and R. C. Stow, "Graston technique on shoulder motion Graston technique on shoulder motion in overhead athletes," Journal of Undergraduate Kinesiology Research, vol. 1, no. 10, pp. 27-39, 2014.

[16] K. Laudner, B. D. Compton, T. A. McLoda, and C. M. Walters, "Acute effects of instrument assisted soft tissue mobilization for improving posterior shoulder range of motion in collegiate baseball players.," International journal of sports physical therapy, vol. 9, no. 1, pp. 1-7, 2014.

[17] M. Terry Loghmani, A. J. Bayliss, G. Clayton, and E. Gundeck, "Successful treatment of a guitarist with a finger joint injury using instrument-assisted soft tissue mobilization: a case report," The Journal of manual \& manipulative therapy, vol. 23, pp. 246-53, 122015.

[18] P. Black et al., "Treatment of knee arthrofibrosis and quadriceps insufficiency after patellar tendon repair: a case report including use of the Graston technique," International Journal of Therapeutic Massage \& Bodywork: Research, Education, \& Practice, vol. 3, no. 2, pp. 14-21, 2010.

[19] H. M. Lee, S. K. Wu, and J. Y. You, "Quantitative application of transverse friction massage and its neurological effects on flexor carpi radialis," Manual Therapy, vol. 14, no. 5, pp. 501-507, 2009.

[20] Q. Wang, H. Zeng, T. M. Best, C. Haas, N. T. Heffner, S. Agarwal, and Y. Zhao, "A mechatronic system for quantitative application and assessment of massage- like actions in small animals," Annals of biomedical engineering, vol. 42, no. 1, pp. $36\{49,2014$.

[21] Femto.io, IMUduino," 2016. [Online]. Available: http://femto.io/products. [Accessed: 21- Feb- 2016].

[22] L. Forsentek Co., Micro compression load cell force sensor

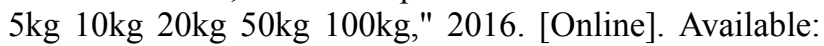
http://www.forsensor.com/. [Accessed: 21- Feb- 2016].

[23] P. G. Agache, C. Monneur, J. L. Leveque, and J. De Rigal, "Mechanical properties and young's modulus of human skin in vivo.," Archives for dermatological research. Archiv fur dermatologische Forschung, vol. 269, pp. 221232, 1980.

[24] G. Elert, The physics hypertextbook, vol. 9. 1998. [Online]. Available: http://physics.info. [Accessed: 21- Feb- 2016].

[25] A. Delalleau, G. Josse, J. Lagarde, H. Zahouani and J. Bergheau, "Characterization of the mechanical properties of skin by inverse analysis combined with the indentation test", Journal of Biomechanics, vol. 39, no. 9, pp. 16031610,2006

[26] A. Gallagher, A. Anniadh, K. Bruyere, M. Otténio, H. Xie and M. Gilchrist, "Dynamic tensile properties of human skin", IRCOBI Conference 2012, vol. -12-59, 2015.

[27] N. Veijgen, M. Masen and E. van der Heide, "A novel approach to measuring the frictional behaviour of human skin in vivo", Tribology International, vol. 54, pp. 38-41, 2012.

[28] Ansys.com, "ANSYS - Simulation Driven Product Development", 2016. [Online]. Available: http://www.ansys.com. 